\title{
Calpain inhibitors: The aspirin of the 21st century?
}

\author{
Juan A. Crestanello, MD
}

\author{
From the Division of Cardiac Surgery, Wexner Medical Center, The Ohio State University, Columbus, Ohio. \\ Disclosures: Author has nothing to disclose with regard to commercial support. \\ Received for publication Oct 17, 2016; accepted for publication Oct 18, 2016; available ahead of print Nov 16, \\ 2016. \\ Address for reprints: Juan A. Crestanello, MD, Wexner Medical Center, Division of Cardiac Surgery, N-820 Doan \\ Hall, 410 W 10th Ave, Columbus, OH 43210 (E-mail: juan.crestanello@osumc.edu). \\ J Thorac Cardiovasc Surg 2017;153:358-9 \\ $0022-5223 / \$ 36.00$ \\ Copyright $\subset 2016$ by The American Association for Thoracic Surgery \\ http://dx.doi.org/10.1016/j.jtcvs.2016.10.025
}

Ischemic heart disease is the leading cause of cardiovascular death and disability, and it is particularly prevalent in patients with metabolic syndrome. ${ }^{1}$ During the last 40 years, such innovative procedures as coronary artery bypass grafting surgery and percutaneous coronary interventions have allowed for the revascularization of epicardial coronary arteries, thus improving blood supply to the ischemic myocardium. Metabolic syndrome, however, is often associated with more extensive coronary atherosclerosis, inflammation, and endothelial and microvascular dysfunction, and this association limits the utility of surgical or percutaneous revascularization in affected patients. ${ }^{2}$ Other revascularization options for patients with metabolic syndrome are currently not available, and as such the progression of ischemia in these patients will lead to myocardial dysfunction, heart failure, and death. Finding alternative revascularization strategies for those patients is thus of paramount importance. This has been a fertile area of research with the use angiogenic growth factors (proteins or genes) or stem cells to stimulate angiogenesis in the ischemic myocardium. ${ }^{3,4}$ These strategies, although successful in the laboratory, have had variable success in clinical practice, mostly because of the challenges associated with the delivery of these agents to the ischemic myocardium.

Calpains are calcium-dependent intracellular proteases that play a key role in cellular homeostasis and cardiac disease. ${ }^{2,5}$ Myocardial ischemia and metabolic syndrome activate calpains, leading to apoptosis, proteolysis of cytoskeletal and contractile proteins, mitochondrial dysfunction, inflammation, atherogenesis, and inhibition of angiogenesis. ${ }^{2,6,7}$ Calpain inhibition may limit these deleterious effects. In their article in this issue of the

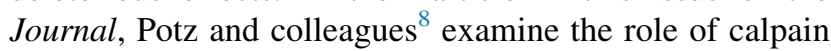
inhibition in a pig model of chronic regional myocardial ischemia in the setting of metabolic syndrome. In their model, calpain inhibition with an orally administered agent stimulates angiogenesis in the ischemic and nonischemic myocardium, leading to increased vessel density and myocardial blood flow. Interestingly, the pathways

\section{References} Circ J. 2016;80:4-10. 2016;310:H455-65

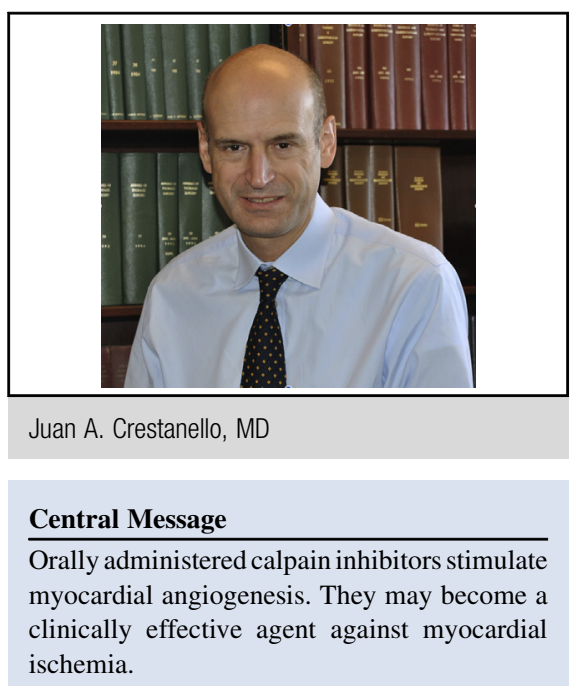

See Article page 342 .

stimulated by calpain inhibition are similar to those activated by angiogenic growth factors.

This study is conceptually important and carries potentially significant clinical implications. It demonstrates that myocardial angiogenesis can be stimulated with an orally administered agent, thus addressing many of the challenges associated with the delivery of angiogenic growth factors or stem cells to the ischemic myocardium. Before considering the administration of a calpain inhibitor to promote angiogenesis in the ischemic myocardium, however, further basic and clinical research is necessary to address several issues, including dosing, absorption, bioavailability, specificity of the inhibition, length of therapy, and, most importantly, safety. It is unknown what the effects of chronically stimulating angiogenesis in the ischemic and nonischemic myocardium and in other organs would be.

Are calpain inhibitors therefore the aspirin of the $21 \mathrm{st}$ century? No, they are not...not yet.

1. Mozaffarian D, Benjamin EJ, Go AS, Arnett DK, Blaha MJ, Cushman M, et al; American Heart Association Statistics Committee; Stroke Statistics Subcommittee, Writing Group Members. Heart disease and stroke statistics-2016 update: a report from the American Heart Association. Circulation. 2016;133:e38-360. Erratum in: Circulation. 2016;133:e599.

2. Potz BA, Sabe AA, Abid MR, Sellke FW. Calpains and coronary vascular disease.

3. Hou L, Kim JJ, Woo YJ, Huang NF. Stem cell-based therapies to promote angiogenesis in ischemic cardiovascular disease. Am J Physiol Heart Circ Physiol. 
4. Rubanyi GM. Angiogenic gene therapy for refractory angina. Expert Opin Biol Ther. 2016;16:303-15.

5. Neuhof C, Neuhof H. Calpain system and its involvement in myocardial ischemia and reperfusion injury. World J Cardiol. 2014;6:638-52.

6. Hua Y, Nair S. Proteases in cardiometabolic diseases: pathophysiology, molecular mechanisms and clinical applications. Biochim Biophys Acta. 2015; 1852:195-208
7. Inserte J, Hernando V, Garcia-Dorado D. Contribution of calpain to myocardial ischaemia/reperfusion injury. Cardiovasc Res. 2012;96: 23-31.

8. Potz BA, Sabe AA, Elmadhun NY, Clements RT, Abid MR, Sodha N, et al. Calpain inhibition modulates GSK-3 $\beta$ pathways in a swine model of chronic myocardial ischemia in the setting of metabolic syndrome: a proteomic and mechanistic analysis. J Thorac Cardiovasc Surg. 2017;153:321-57. 